\title{
Sex differences in health status, healthcare utilization, and costs among individuals with elevated blood pressure: the LARK study from Western Kenya
}

Neha Sikka', Allison DeLong², Jemima Kamano ${ }^{3}$, Sylvester Kimaiyo ${ }^{3}$, Vitalis Orango ${ }^{4}$, Josephine Andesia ${ }^{4}$, Valentin Fuster ${ }^{1}$, Joseph Hogan ${ }^{2,5}$ and Rajesh Vedanthan ${ }^{6^{*}}$ (D)

\begin{abstract}
Background: Elevated blood pressure is the leading risk factor for global mortality. While it is known that there exist differences between men and women with respect to socioeconomic status, self-reported health, and healthcare utilization, there are few published studies from Africa. This study therefore aims to characterize differences in selfreported health status, healthcare utilization, and costs between men and women with elevated blood pressure in Kenya.

Methods: Data from 1447 participants enrolled in the LARK Hypertension study in western Kenya were analyzed. Latent class analysis based on five dependent variables was performed to describe patterns of healthcare utilization and costs in the study population. Regression analysis was then performed to describe the relationship between different demographics and each outcome.

Results: Women in our study had higher rates of unemployment ( $28 \%$ vs $12 \%$ ), were more likely to report lower monthly earnings ( $72 \%$ vs $51 \%$ ), and had more outpatient visits (39\% vs $28 \%$ ) and pharmacy prescriptions (42\% vs $30 \%)$. Women were also more likely to report lower quality-of-life and functional health status, including pain, mobility, self-care, and ability to perform usual activities. Three patterns of healthcare utilization were described: (1) individuals with low healthcare utilization, (2) individuals who utilized care and paid high out-of-pocket costs, and (3) individuals who utilized care but had lower out-of-pocket costs. Women and those with health insurance were more likely to be in the high-cost utilizer group.
\end{abstract}

Conclusions: Men and women with elevated blood pressure in Kenya have different health care utilization behaviors, cost and economic burdens, and self-perceived health status. Awareness of these sex differences can help inform targeted interventions in these populations.

Keywords: Hypertension, Sex differences, Healthcare utilization, Healthcare costs

\footnotetext{
* Correspondence: rajesh.vedanthan@nyulangone.org

${ }^{6}$ Department of Population Health, NYU Grossman School of Medicine, New York, NY, USA

Full list of author information is available at the end of the article
}

(c) The Author(s). 2021 Open Access This article is licensed under a Creative Commons Attribution 4.0 International License, which permits use, sharing, adaptation, distribution and reproduction in any medium or format, as long as you give appropriate credit to the original author(s) and the source, provide a link to the Creative Commons licence, and indicate if changes were made. The images or other third party material in this article are included in the article's Creative Commons licence, unless indicated otherwise in a credit line to the material. If material is not included in the article's Creative Commons licence and your intended use is not permitted by statutory regulation or exceeds the permitted use, you will need to obtain permission directly from the copyright holder. To view a copy of this licence, visit http://creativecommons.org/licenses/by/4.0/. The Creative Commons Public Domain Dedication waiver (http://creativecommons.org/publicdomain/zero/1.0/) applies to the data made available in this article, unless otherwise stated in a credit line to the data. 


\section{Background}

Elevated blood pressure is the leading global risk factor for mortality and the most common cardiovascular condition in the world [1]. Despite $80 \%$ of all cardiovascularrelated deaths occurring in low- and middle-income countries, health care utilization in these populations remains low $[2,3]$. Differences in healthcare utilization by sex have been widely reported, with higher use by women [4-6]. This higher utilization is furthermore associated with increased healthcare costs $[6,7]$.

Healthcare utilization is influenced by three groups of factors: "predisposing factors" which include sex along with age, educational level, marital status, and trust level in healthcare influence; "enabling/inhibiting factors" such as medical insurance, wealth, and availability of medical care; and need for care (Fig. 1) [8, 9]. Emerging literature has supported sex differences in relation to many of these individual characteristics. For instance, the 2007-2016 NHANES survey of US civilian populations found higher awareness, treatment, and blood pressure control rates in women age less than 65 years with hypertension of all races [10], despite general lower rates of employment and lower income compared to men of the same status $[11,12]$. However, characterizations of the differences in health care utilization, cost, and associated factors between men and women with elevated blood pressure is limited in African populations.

We therefore sought to describe the patterns and costs of health care utilization of men and women with elevated blood pressure in western Kenya along with characteristics that may affect these patterns. The LARK Hypertension study is a cluster randomized controlled trial that demonstrated that community health workers, equipped with behavioral communication strategies and smartphone decision-support tools, can increase linkage to hypertension care and yield modestly improved but not statistically significant blood pressure reduction among individuals with hypertension in rural Western Kenya [13]. We present here an analysis of baseline data from the trial, focusing on sex differences in selfreported health status, healthcare utilization, and costs in this population.

\section{Methods}

\section{Study setting and participants}

The LARK study was conducted within the infrastructure of the Academic Model Providing Access to Healthcare Partnership (AMPATH) in Kenya [14, 15]. It was conducted within two administrative divisions in rural western Kenya: Kosirai and Turbo. From April 2014 to December 2016, adult individuals who met the study inclusion criterion of elevated blood pressure (defined as systolic blood pressure $(\mathrm{SBP}) \geq 140 \mathrm{mg} / \mathrm{dL}$ or diastolic blood pressure $(\mathrm{DBP}) \geq 90 \mathrm{mg} / \mathrm{dL}$ ) were invited and consented into the LARK study. Individuals without elevated blood pressure, those who did not provide informed consent, or those who were critically ill were excluded. Individuals who were actively engaged in hypertension care were also excluded. Overall, the LARK study enrolled 1460 participants. Full data for the present

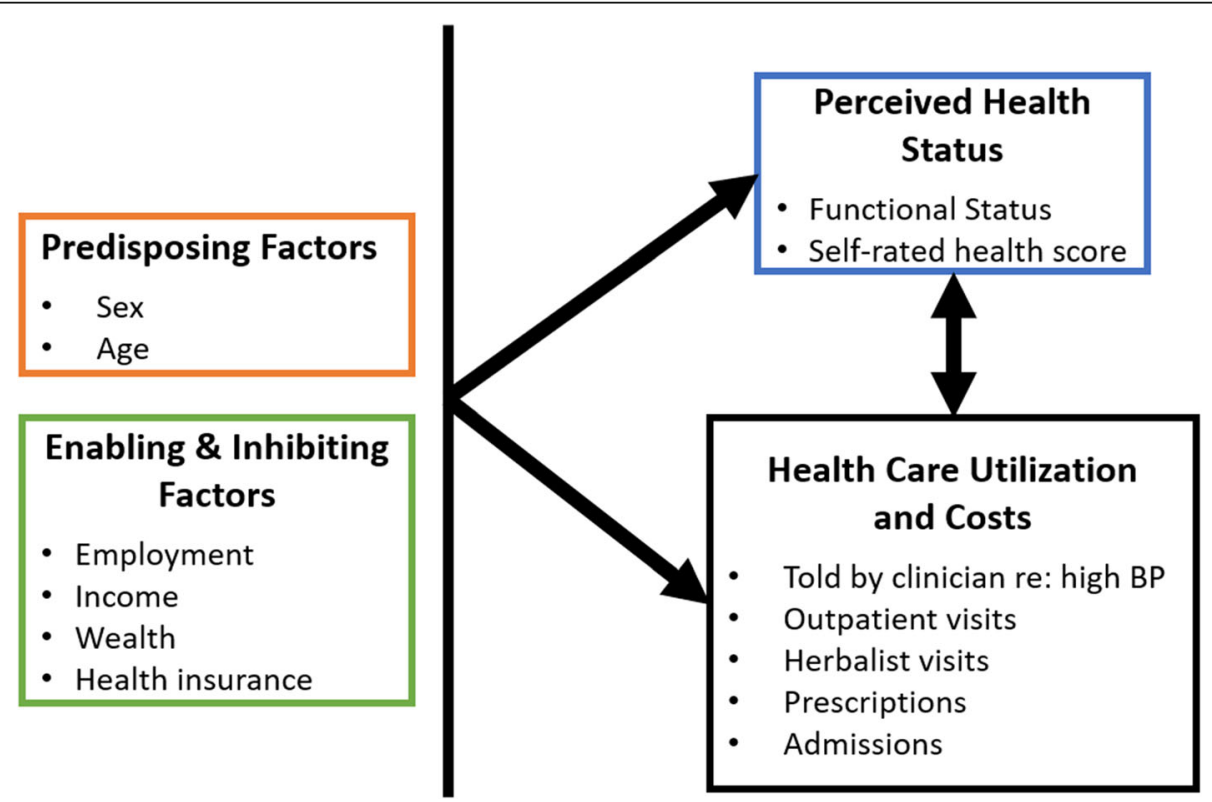

Fig. 1 Factors that may impact healthcare utilization. Potential variables examined in this study, categorized as predisposing factors, enabling/ inhibiting factors, and perceived health status 
analysis were available for 1447 participants. Written informed consent was obtained from all participants. Detailed study procedures have previously been fully reported [14].

\section{Survey}

The baseline questionnaire collected data about employment status, field of employment, and reason for unemployment when relevant. Monthly income was asked in 5000 to 10,000 Kenyan shilling (KS) increments (roughly equivalent to $\$ 50-\$ 100$ increments). Participants were asked whether they had health insurance, including the Kenyan National Health Insurance Fund (NHIF). All participants were asked if they had been told about their elevated blood pressure by a healthcare worker or doctor in the past 12 months. Rates of health care utilization were determined by questions on numbers of admissions to a hospital (in-patient) over the past 12 months, and number of visits to an outpatient medical provider, herbalist, or spiritual provider over the past 3 months. Participants with any of the previous visits were asked for their out-of-pocket costs for the visit. Additionally, participants were asked about medications they were prescribed and associated cost. To approximate quality-of-life status, participants were asked about mobility, self-care, ability to perform usual activities, pain, and anxiety/depression. Participants were also asked to score their health status on a scale of $0-100$, with 0 being "the worst health you can imagine" and 100 being "the best health you can imagine" [16]. All items in the questionnaire were ascertained by self-report. Sex ("male" or "female") of each participant was recorded by the clinician in the clinical encounter form. All baseline questionnaire data were collected prior to any LARK study intervention.

\section{Data analysis}

Demographic, socioeconomic and health status variables and self-reported measures healthcare utilization over the past 3 or 12 months were summarized overall and separately for men and women. Categorical measures were expressed using counts, and percentages and continuous measures using median and interquartile range (IQR). Data were analyzed using R version 3.6.1 [17].

\section{Health utilization and costs}

Latent class regression analysis (LCA) was used to describe patterns of healthcare utilization and costs in our population [18]. A latent class distribution was assumed to describe the joint distribution of five manifest (dependent) variables: one binary variable (whether they had been told by a health worker or doctor they had high blood pressure in past 12 months (with the $27 \mathrm{ob}$ servations with missing values omitted)); and four multinomial variables, each with three mutually exclusive classes (1): cost of hospital admissions in the past 12 months (no admission, less than $5000 \mathrm{KS}$ ( 50 USD), more than $5000 \mathrm{KS})$ (2); cost of outpatient visit in the past 3 months (no outpatient visit, less than $200 \mathrm{KS}(\sim 2$ USD), more than $200 \mathrm{KS}$ ) (3); cost of visit to a herbal medicine or spiritual healer in the past 3 months (no herbal medicine/spiritual healer visit, less than $200 \mathrm{KS}$, more than $200 \mathrm{KS}$ ); and (4) cost of prescription medication filled in the past 3 months (no prescriptions, less than $200 \mathrm{KS}$, more than $200 \mathrm{KS}$ ). Cut-offs for cost variables were based on the data including median cost values and burden based on income. Since "being told by a healthcare worker about high blood pressure status" may not fully reflect healthcare utilization of all participants, we performed a secondary LCA without this manifest variable.

The patterns of health utilization and costs for each latent class were described and an informative label was assigned to each class, anticipating finding LCA groups pertaining to low, medium, and high health care use and costs. The probability of belonging in each latent class was captured for each participant. For descriptive summaries, participants were assigned to the class with the highest probability.

The latent class regression analysis allowed the dependent manifest variables to be modeled as a function of covariates. We allowed latent class membership probability to be dependent on sex, age group $(<50,50-64$, $>=65$ ), health insurance status, employment and income status as a 3-level variable (no job, monthly earnings < $5000 \mathrm{KS}$, and earnings $>=5000 \mathrm{KS}$ ), and community unit [19]. Observations with missing data $(n=108(7.5 \%))$ were omitted from this analysis. Using the largest latent class as the reference, we generated relative risk ratios of latent class membership for the other classes by sex, age, insurance, and employment/income status. LCA models were fit using the poLCA R package [19]. The Akaike information criterion (AIC) was used for model selection [17].

\section{Utilization and self-reported health}

Self-reported health status was summarized by latent class assignment. To examine our primary hypothesis that there were sex differences in health status, utilization and costs, we regressed the self-reported health measures on latent class membership probability and gender, adjusting for demographics. Specifically, for each of the 6 health status measures ( 5 binomial and 1 continuous), a mixed effects regression model with a random effect for community unit was used to examine the relationship between each health status as the dependent variable and the probability of latent class membership (using the largest group as the reference) and sex. All models included covariates for age group, health insurance status, and employment and 
Table 1 Summary of participant demographic characteristics and self-rated health by sex

\begin{tabular}{|c|c|c|c|}
\hline Category & Total $N=1447$ & Female $N=838$ & Male $N=609$ \\
\hline Age (years) & $55.0(42.0,66.0)$ & $54.0(42.0,65.0)$ & $56.0(40.0,67.0)$ \\
\hline \multicolumn{4}{|l|}{ Employment } \\
\hline No Job & $304(21)$ & $231(28)$ & $73(12)$ \\
\hline Farmer & $728(50)$ & $431(51)$ & $297(49)$ \\
\hline Business Person & $185(13)$ & $104(12)$ & $81(13)$ \\
\hline Public Sector Employee & $54(4)$ & $17(2)$ & $37(6)$ \\
\hline Student & $4(0)$ & $3(0)$ & $1(0)$ \\
\hline Other & $150(10)$ & $43(5)$ & $107(18)$ \\
\hline Missing & $22(2)$ & $9(1)$ & $13(2)$ \\
\hline \multicolumn{4}{|l|}{ Reason for Not Working } \\
\hline Retired or too old & $138(45)$ & $92(40)$ & $46(63)$ \\
\hline Caring for Family & $68(22)$ & $65(28)$ & $3(4)$ \\
\hline Could not find or get work & $41(13)$ & $31(13)$ & $10(14)$ \\
\hline Illness or Disability & $38(12)$ & $32(14)$ & $6(8)$ \\
\hline In School & $6(2)$ & $1(0)$ & $5(7)$ \\
\hline Temporary Gap in Employment & $5(2)$ & $4(2)$ & $1(1)$ \\
\hline Other & $8(3)$ & $6(3)$ & $2(3)$ \\
\hline \multicolumn{4}{|c|}{ Monthly Earnings Among Working (KS) } \\
\hline$<5000$ & $712(62)$ & $438(72)$ & $274(51)$ \\
\hline$\geq 5000 \&<10,000$ & $198(17)$ & $78(13)$ & $120(22)$ \\
\hline$\geq 10,000 \&<20,000$ & $78(7)$ & $23(4)$ & $55(10)$ \\
\hline$\geq 20,000 \&<30,000$ & $36(3)$ & $13(2)$ & $23(4)$ \\
\hline$\geq 30,000$ & $28(2)$ & $8(1)$ & $20(4)$ \\
\hline Missing & $91(8)$ & $47(8)$ & $44(8)$ \\
\hline \multicolumn{4}{|l|}{ Have NHIF } \\
\hline Yes & $213(15)$ & $110(13)$ & $103(17)$ \\
\hline No & $1205(83)$ & $712(85)$ & $493(81)$ \\
\hline Missing & $29(2)$ & $16(2)$ & $13(2)$ \\
\hline \multicolumn{4}{|l|}{ How would you describe your pain? } \\
\hline No pain & $721(50)$ & $349(42)$ & $372(61)$ \\
\hline Moderate pain & $677(47)$ & $459(55)$ & $218(36)$ \\
\hline Extreme pain & $28(2)$ & $22(3)$ & $6(1)$ \\
\hline Missing & $21(1)$ & $8(1)$ & $13(2)$ \\
\hline \multicolumn{4}{|c|}{ How would you describe your anxiety or depression? } \\
\hline Not anxious & $635(44)$ & $318(38)$ & $317(52)$ \\
\hline Moderately anxious & $671(46)$ & $428(51)$ & $243(40)$ \\
\hline Extremely anxious or depressed & $120(8)$ & $84(10)$ & $36(6)$ \\
\hline Missing & $21(1)$ & $8(1)$ & $13(2)$ \\
\hline \multicolumn{4}{|c|}{ How would you describe your mobility? } \\
\hline No problems in walking & $972(67)$ & $517(62)$ & $455(75)$ \\
\hline Some problems in walking & $448(31)$ & $308(37)$ & $140(23)$ \\
\hline Confined to bed & $3(0)$ & $2(0)$ & $1(0)$ \\
\hline Missing & $24(2)$ & $11(1)$ & $13(2)$ \\
\hline
\end{tabular}

How would you describe your self-care? 
Table 1 Summary of participant demographic characteristics and self-rated health by sex (Continued)

\begin{tabular}{|c|c|c|c|}
\hline Category & Total $N=1447$ & Female $N=838$ & Male $N=609$ \\
\hline No problems with self-care & $1321(91)$ & $759(91)$ & $562(92)$ \\
\hline Some problems washing or dressing & $98(7)$ & $66(8)$ & $32(5)$ \\
\hline Unable to wash or dress myself & $6(0)$ & $4(0)$ & $2(0)$ \\
\hline Missing & $22(2)$ & $9(1)$ & $13(2)$ \\
\hline \multicolumn{4}{|l|}{ How would you describe your usual activities? } \\
\hline No problems with usual activity & $1148(79)$ & $632(75)$ & $516(85)$ \\
\hline Some problems performing usual activity & $257(18)$ & $185(22)$ & $72(12)$ \\
\hline Unable to perform usual activity & $18(1)$ & $11(1)$ & $7(1)$ \\
\hline Missing & $24(2)$ & $10(1)$ & $14(2)$ \\
\hline \multicolumn{4}{|l|}{ How is your health today, $0-100 ?$} \\
\hline & $70.0(60.0,80.0)$ & $70.0(60.0,80.0)$ & $75.0(65.0,82.5)$ \\
\hline Missing & 22 & 8 & 14 \\
\hline
\end{tabular}

income status. For the continuous health score, the effects measured the difference in health status. For the binomial symptom measures (pain, anxiety and depression, mobility, self-care, and ability to complete usual activities) we used logistic mixed effects models and compared having any symptoms to no symptoms using the odds ratio (OR).

\section{Results}

\section{Demographics and self-rated health}

Of the 1447 participants, 58\% were women. Women were more likely to be unemployed (Table 1). Of those not working, $40 \%$ of women and $63 \%$ of men indicated they were retired or too old. Excluding this, the top reason for not working reported by women was that they were caring for family, whereas for men, the next most cited reason was inability to find work. Among those with formal employment, women were more likely to report earning less than $5000 \mathrm{KS}$ ( 50 USD) per month. A large proportion of the study population was not enrolled in health insurance of any type, with only $13 \%$ of women and $17 \%$ of men indicating enrollment in Kenyan NHIF. Women reported worse self-reported qualityof-life than men, with more women reporting issues with mobility, ability to perform usual activities, pain, anxiety and depression, and lower overall median health score compared to men.

\section{Healthcare utilization and associated costs}

Women reported higher rates of having been told about their elevated blood pressure within the past 12 months, attendance at an outpatient medical visit, and taking prescription medication (Table 2). Women and men had similar low rates of hospital admissions over the previous 12 months, with less than $1 \%$ of the participants having multiple admissions. Men and women also had similar rates of visits to herbalists or spiritual leaders, with almost one-fifth of participants seeking these alternative care sources. A higher proportion of women had no costs for their outpatient visits, though a lower proportion of women paid $\leq 200 \mathrm{KS}$ for their outpatient visit compared to men. Similarly, a higher proportion of women paid no cost for herbalist visits, but a lower proportion of women paid $\leq 200 \mathrm{KS}$ for their herbalist visit.

\section{Classes of healthcare utilization and costs}

LCA showed optimal AIC with a three-class model (Supplemental Table 1). Details of the three classes used in the LCA are shown in Supplemental Table 2. Secondary LCA without the variable related to being told about high blood pressure produced nearly indistinguishable results to the primary LCA (Supplemental Figure 1).

The largest class, "non-utilizers", comprised $60 \%$ of the population and had little to no health utilization outside of herbalist and spiritual healers (Fig. 2, Table 3). The next largest class, characterized as "high-cost utilizers", comprised $21 \%$ of the population and reported engagement with the medical system with high cost of care (with outpatient bills and prescriptions $>200 \mathrm{KS}(\sim 2$ USD)). The smallest class, characterized as "low-cost utilizers", comprised $19 \%$ of the population and reported engagement with the medical system through outpatient visits and prescriptions with low cost of care (no outpatient bills and few prescriptions $>200 \mathrm{KS}(\sim 2 \mathrm{USD})$ ).

Non-utilizers had the largest proportion of men (47\%) and high cost-utilizers had the largest proportion of women (67\%) (Supplemental Table 2). High-cost utilizers were disproportionately younger, with $42 \%$ of the group less than the age of 50 years. Income distribution was similar across the three classes. Interestingly, highcost utilizers had the highest rate of enrollment national insurance at $19 \%$. 
Table 2 Healthcare utilization and cost by sex

\begin{tabular}{|c|c|c|c|c|}
\hline Category & Value & Total $N=1447$ & Female $N=838$ & Male $N=609$ \\
\hline \multicolumn{5}{|c|}{ Told have high BP in past 12 months? } \\
\hline & Yes & $585(40)$ & $380(45)$ & $205(34)$ \\
\hline & No & $835(58)$ & $445(53)$ & $390(64)$ \\
\hline & Missing & $27(2)$ & $13(2)$ & $14(2)$ \\
\hline \multicolumn{5}{|c|}{ One or more hospitalization } \\
\hline & Yes & $56(4)$ & $36(4)$ & $20(3)$ \\
\hline & No & $1391(96)$ & $802(96)$ & $589(97)$ \\
\hline \multicolumn{5}{|c|}{ Inpatient Cost } \\
\hline & No Cost for Visit & $20(36)$ & $13(36)$ & $7(35)$ \\
\hline & $\leq 5000 \mathrm{KS}$ & $21(38)$ & $13(36)$ & $8(40)$ \\
\hline & $>5000 \mathrm{KS}$ & $15(27)$ & $10(28)$ & $5(25)$ \\
\hline \multicolumn{5}{|c|}{ Any Outpatient Visit past 12 months } \\
\hline & Yes & 499 (34) & $327(39)$ & $172(28)$ \\
\hline & No & $948(66)$ & $511(61)$ & $437(72)$ \\
\hline \multicolumn{5}{|c|}{ Outpatient Cost } \\
\hline & No Cost for Visit & $154(31)$ & $110(34)$ & $44(26)$ \\
\hline & $\leq 200 \mathrm{KS}$ & $122(24)$ & $67(20)$ & $55(32)$ \\
\hline & $>200 \mathrm{KS}$ & $223(45)$ & $150(46)$ & $73(42)$ \\
\hline \multicolumn{5}{|c|}{ Ever go to Herbalist } \\
\hline & Yes & $271(19)$ & $166(20)$ & $105(17)$ \\
\hline & No & $1176(81)$ & $672(80)$ & $504(83)$ \\
\hline \multicolumn{5}{|c|}{ Herbal Cost } \\
\hline & No Cost for Visit & $136(50)$ & $90(54)$ & $46(44)$ \\
\hline & $\leq 200 \mathrm{KS}$ & $69(25)$ & $33(20)$ & $36(34)$ \\
\hline & $>200 \mathrm{KS}$ & $66(4)$ & $43(26)$ & $23(22)$ \\
\hline \multicolumn{5}{|c|}{ Any Prescription } \\
\hline & Yes & $538(37)$ & $354(42)$ & $184(30)$ \\
\hline & No & $909(63)$ & $484(58)$ & $425(70)$ \\
\hline \multicolumn{5}{|c|}{ Prescription Cost } \\
\hline & No Cost for Prescription & $191(36)$ & $134(38)$ & $57(31)$ \\
\hline & $\leq 200 \mathrm{KS}$ & $65(12)$ & $42(12)$ & $23(13)$ \\
\hline & $>200 \mathrm{KS}$ & $282(52)$ & $178(50)$ & $104(57)$ \\
\hline
\end{tabular}

Costs are presented in Kenyan Shillings (KS) and presented only for individuals that reported utilizing that health resource. Continuous variables are presented as "median (IQR)" and categorical variables as N (\%). Percentages are by column

Relative risk calculations showed sex and insurance had the strongest effect on membership in a healthcare utilization class: Women had 1.71 (95\% CI: 1.22 to 2.42$)$ times the odds of being in the high-cost utilizer class versus the non-utilization class compared to men, and 1.52 (95\% CI: 1.07 to 2.15 ) times the odds of being in the low-cost utilizer class. Having national insurance was significantly associated with membership in the high-cost utilizer class with an odds ratio of 1.93 (95\% CI: 1.26 to 2.97) (Fig. 3, Supplemental Table 3).

\section{Self-reported health status}

The high-cost utilizer and low-cost utilizer class had similar higher rates of participants reporting difficulty with mobility, self-care, completing usual activities, and lower overall health score compared to the non-utilizer class (Table 4). The high-cost utilizer class had the highest rate of participants reporting pain. Overall, membership in the high-cost utilizer class was associated with a worse self-reported health (difference: -4.03 ) and more problems with pain (OR 1.70), mobility (OR 1.97), self- 


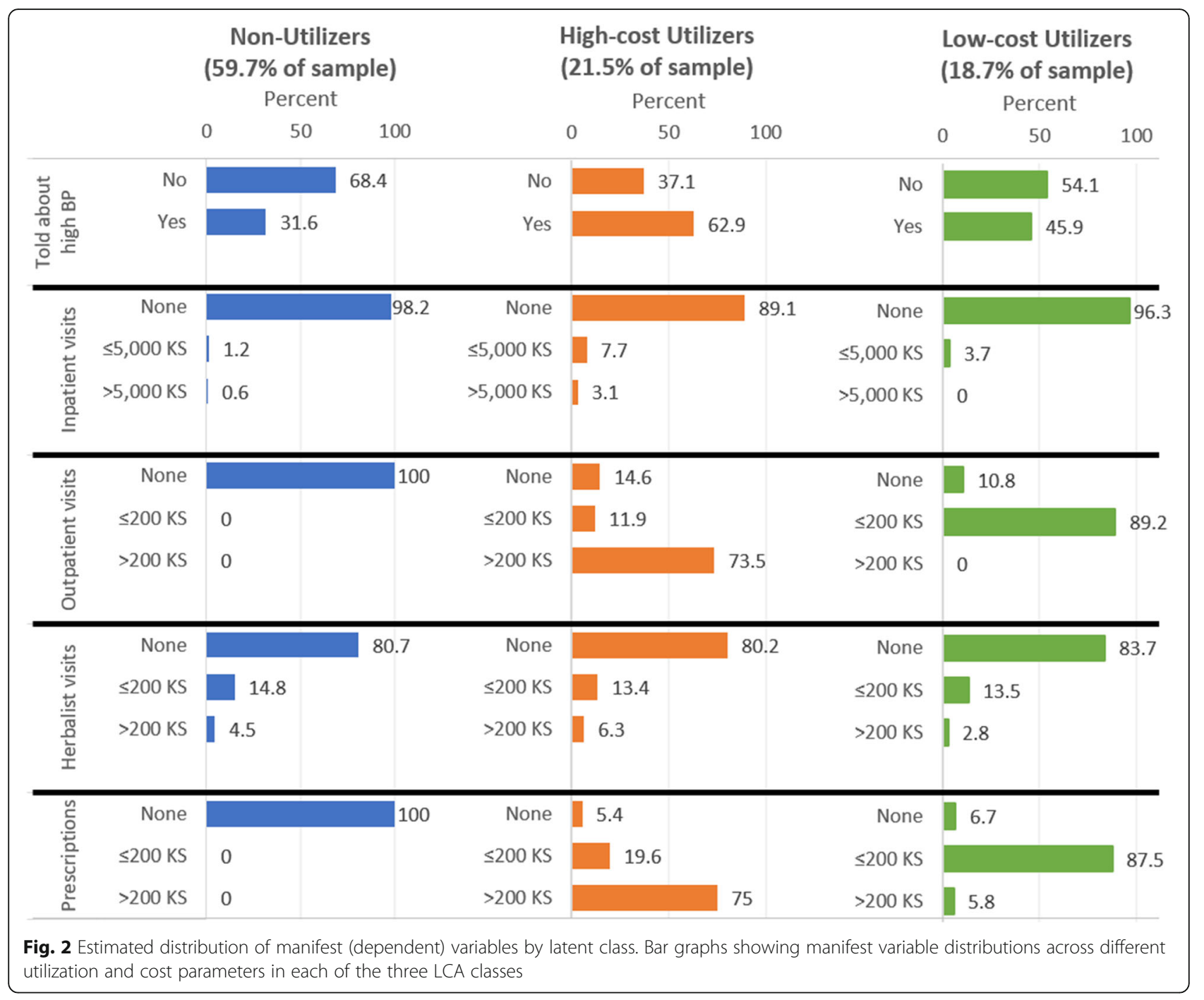

care (OR 2.09), and usual activities (OR 2.57). Similarly, being in the low-cost utilizer class was associated with worse self-reported health (difference: -4.55$)$ and more problems with mobility (OR 1.69), self-care (OR 1.81), and usual activities (OR 1.79) than membership in the non-utilizer class (Table 4).

Even after accounting for latent class membership probability, being a woman was associated with worse self-reported health (difference: -1.49 ) and more problems with pain (OR 2.04), anxiety/depression (OR 1.78), mobility (OR 1.74), and performing usual activities (OR 1.67). Other demographic variables also were associated with self-reported health status. Older age was associated with worse health score, pain, mobility, self-care, and ability to perform usual activities with strengthened associations for the oldest age group. Similarly, earning no income was associated with worsened pain, anxiety and depression, mobility, self-care, and ability to perform usual activities than those earning greater than 5000KS.
Having health insurance was associated with increased reported pain.

\section{Discussion}

Our analysis of 1447 adults with elevated blood pressure in rural Kenya revealed that women were of poorer socio-economic status, had poorer self-reported health status, and greater healthcare utilization of outpatient visits and medication prescriptions compared to men. Three distinct patterns emerged among the entire study cohort: health care utilizers with high medical costs, health care utilizers with low medical costs, and nonutilizers. Being female and having insurance had the most influence on being in a health-utilizing class. However, across all classes, women experienced worse functional health status than men.

Our finding of greater health care utilization by women is consistent with previous reports from Kenya [20], as well as other parts of the world [3, 4, 6, 21-23]. 
Table 3 Description of health status variables stratified by the 3 latent classes

\begin{tabular}{|c|c|c|c|c|c|}
\hline Category & Value & $\begin{array}{l}\text { Total } N= \\
1339\end{array}$ & $\begin{array}{l}\text { Non-utilizers } N= \\
821\end{array}$ & $\begin{array}{l}\text { High-cost utilizers } N= \\
279\end{array}$ & $\begin{array}{l}\text { Low-cost utilizers } N= \\
256\end{array}$ \\
\hline \multicolumn{6}{|c|}{ How would you describe your mobility? } \\
\hline & No problems in walking & $909(68)$ & $592(74)$ & $163(58)$ & $154(60)$ \\
\hline & Some problems in walking & $424(32)$ & $209(26)$ & $113(41)$ & $102(40)$ \\
\hline & Confined to bed & $3(0)$ & $0(0)$ & $3(1)$ & $0(0)$ \\
\hline & Missing & $3(0)$ & $3(0)$ & $0(0)$ & $0(0)$ \\
\hline \multicolumn{6}{|c|}{ How would you describe your self-care? } \\
\hline & No problems with self-care & $1236(92)$ & $757(94)$ & $250(90)$ & $229(89)$ \\
\hline & Some problems washing or dressing & $96(7)$ & $45(6)$ & $27(10)$ & $24(9)$ \\
\hline & Unable to wash or dress myself & $6(0)$ & $1(0)$ & $2(1)$ & $3(1)$ \\
\hline & Missing & $1(0)$ & $1(0)$ & $0(0)$ & $0(0)$ \\
\hline \multicolumn{6}{|c|}{ How would you describe your usual activities? } \\
\hline & No problems with usual activity & $1068(80)$ & $682(85)$ & $197(71)$ & $189(74)$ \\
\hline & $\begin{array}{l}\text { Some problems performing usual } \\
\text { activity }\end{array}$ & $250(19)$ & $112(14)$ & $73(26)$ & $65(25)$ \\
\hline & Unable to perform usual activity & $18(1)$ & $7(1)$ & $9(3)$ & $2(1)$ \\
\hline & Missing & $3(0)$ & $3(0)$ & $0(0)$ & $0(0)$ \\
\hline \multicolumn{6}{|c|}{ How would you describe your pain? } \\
\hline & No pain & $685(51)$ & $448(56)$ & $115(41)$ & $122(48)$ \\
\hline & Moderate pain & $630(47)$ & $348(43)$ & $156(56)$ & $126(49)$ \\
\hline & Extreme pain & $24(2)$ & $8(1)$ & $8(3)$ & $8(3)$ \\
\hline \multicolumn{6}{|c|}{ How would you describe your anxiety or depression? } \\
\hline & Not anxious & $599(45)$ & $357(44)$ & $131(47)$ & $111(43)$ \\
\hline & Moderately anxious & $633(47)$ & $395(49)$ & $114(41)$ & $124(48)$ \\
\hline & Extremely anxious or depressed & $107(8)$ & $52(6)$ & $34(12)$ & $21(8)$ \\
\hline \multicolumn{6}{|c|}{ How is your health today, $0-100 ?$} \\
\hline & & $\begin{array}{l}75.0(60.0, \\
80.0)\end{array}$ & $75.0(65.0,85.0)$ & $70.0(60.0,80.0)$ & $70.0(60.0,80.0)$ \\
\hline & Missing & 1 & 1 & 0 & 0 \\
\hline
\end{tabular}

Women overall reported worse functional health status, possibly contributing to a higher perceived healthcare need as shown in other study populations [9, 24, 25]. However, there were some notable differences and patterns that were illuminated by our latent class analysis. First, individuals with no or low utilization of health care services also had lower awareness of their elevated blood pressure. However, one-third to one-half of these individuals did endorse knowing about their elevated blood pressure, yet did not utilize healthcare. These findings are consistent with literature from other parts of the world that have described gaps in the hypertension care cascade $[26,27]$. It is also possible that those nonutilizers who were aware of their elevated blood pressure faced competing obligations, such as concern about work and employment, which constrained health careseeking behavior. Finally, contrary to what has been reported in other populations $[4,28,29]$, our latent class analysis indicated that the level of healthcare utilization was similar across incomes of those employed. This unexpected finding merits further inquiry, and research is needed to clarify the factors that may impact health care utilization.

Our latent class analysis revealed one group of individuals who face higher health costs while having lower incomes. This combination of low income and high health costs is clearly concerning and highlights the urgent need for financial risk protection such as health insurance. Notably, the rates of national insurance (NHIF) enrollment among our participants was very low, with only $13 \%$ of women and $17 \%$ of men reporting current enrollment, in line with national statistics [30]. While we found that those with the highest healthcare costs had the highest rates of enrollment in NHIF, we were not able to determine whether the NHIF enrollment was initiated before or after the high-cost health care experience. 


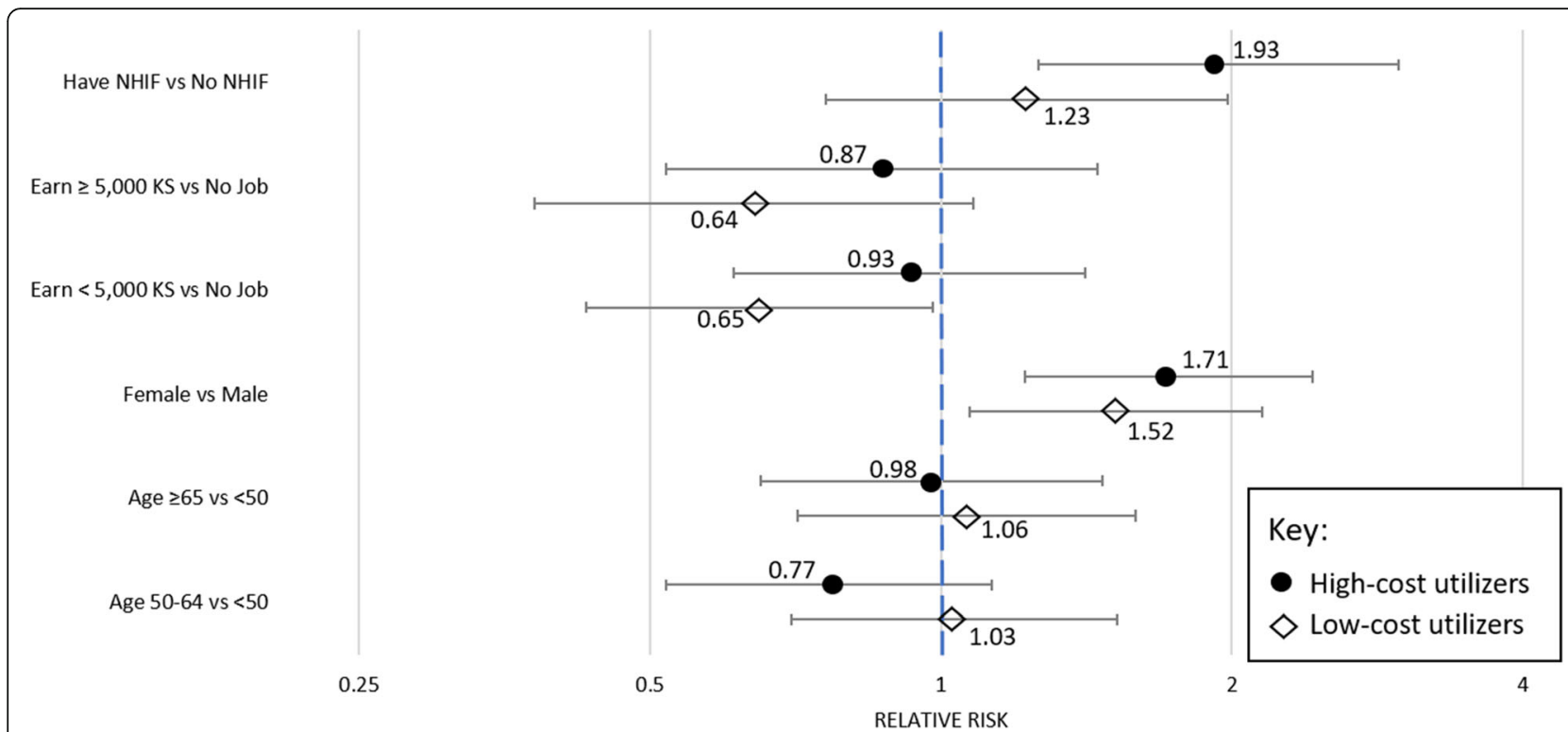

Fig. 3 Relative risk of latent class membership by demographic. Relative risk of latent class membership probability compared to the largest, nonutilizer class. Error bars show 95\% confidence intervals. Black dots indicate high-cost utilizer class compared to non-utilizers. White diamonds indicate low-cost utilizer class compared to non-utilizers. Please note the $x$-axis is logarithmic base 2 . Numeric values can be found in supplement Table 3

Additionally, it is worth noting that NHIF does not cover the cost of visits to herbalists or spiritual healers, seen by a substantial proportion of participants in our study, thus increasing the out-of-pocket burden for those individuals. In addition, efforts to medically engage this population need to consider collaborating with these practitioners, to maximize the reach across different segments of the population. Partnering with nontraditional medical providers in communities has been shown to be beneficial with respect to building trust and improving blood pressure control [31-33].

Kenya is considered a lower middle-income country with a $40 \%$ national unemployment rate and $36.1 \%$ of the country living under the international poverty line ( $\$ 1.90 /$ day, $\sim 5700 \mathrm{KS} /$ month) [34-36]. In our rural, agricultural participant population, reported unemployment rates were lower than the national average, about $21 \%$, but almost $70 \%$ of our participants lived under the poverty line. Women felt this burden unequally, with lower rates of employment and income than men. These economic challenges have been documented in numerous countries worldwide [37]. These factors may contribute to previously studied differences in health seeking behaviors between rural and urban populations [38, 39].

Several potential strategies to improve the implementation gap with respect to blood pressure treatment and

Table 4 Regressions of health status on health utilization latent class membership, gender, and other covariates

\begin{tabular}{|c|c|c|c|c|c|c|}
\hline & $\begin{array}{l}\text { Self-Reported Health } \\
\text { (Diff, 95\% Cl) }\end{array}$ & $\begin{array}{l}\text { Pain } \\
\text { (OR, Cl) }\end{array}$ & $\begin{array}{l}\text { Anxiety and Depression } \\
\text { (OR, CI) }\end{array}$ & $\begin{array}{l}\text { Mobility } \\
\text { (OR, Cl) }\end{array}$ & $\begin{array}{l}\text { Self Care } \\
(\mathrm{OR}, \mathrm{Cl})\end{array}$ & $\begin{array}{l}\text { Usual Activities } \\
\text { (OR, Cl) }\end{array}$ \\
\hline $\begin{array}{l}\text { High-cost utilizer } \\
\text { vs Non-utilizer }\end{array}$ & $-4.03(-5.93,-2.17)$ & $1.70(1.25,2.31)$ & $1.67(0.99,2.80)$ & $1.97(1.43,2.72)$ & $2.09(1.22,3.57)$ & $2.57(1.80,3.68)$ \\
\hline $\begin{array}{l}\text { Low-cost utilizer } \\
\text { vs Non-utilizer }\end{array}$ & $-4.55(-6.52,-2.61)$ & $1.20(0.88,1.65)$ & $1.30(0.72,2.35)$ & $1.69(1.21,2.36)$ & $1.81(1.04,3.14)$ & $1.79(1.22,2.62)$ \\
\hline Female vs Male & $-1.49(-2.99,0.02)$ & $2.04(1.60,2.61)$ & $1.78(1.11,2.85)$ & $1.74(1.33,2.28)$ & $1.16(0.72,1.86)$ & $1.67(1.21,2.31)$ \\
\hline Age $50-64$ vs $<50$ & $-2.16(-3.82,-0.50)$ & $1.89(1.44,2.49)$ & $1.09(0.66,1.79)$ & $1.72(1.26,2.33)$ & $2.73(1.39,5.38)$ & $1.94(1.33,2.83)$ \\
\hline Age $\geq 65$ vs $<50$ & $-6.03(-7.85,-4.21)$ & $3.05(2.25,4.13)$ & $0.93(0.54,1.62)$ & $3.19(2.31,4.41)$ & $5.15(2.70,9.83)$ & $3.19(2.19,4.67)$ \\
\hline Have NHIF vs Not & $1.61(-0.39,3.64)$ & $1.44(1.03,2.00)$ & $0.81(0.42,1.56)$ & $0.87(0.60,1.25)$ & $0.63(0.30,1.32)$ & $0.85(0.55,1.31)$ \\
\hline Earn $<5000$ KS vs No Job & $1.63(-0.28,3.53)$ & $0.82(0.60,1.12)$ & $1.74(0.97,3.12)$ & $0.75(0.54,1.03)$ & $0.33(0.20,0.54)$ & $0.41(0.29,0.58)$ \\
\hline Earn $\geq 5000$ KS vs No Job & $5.02(2.72,7.32)$ & $0.55(0.38,0.80)$ & $0.88(0.42,1.85)$ & $0.50(0.33,0.76)$ & $0.38(0.19,0.75)$ & $0.35(0.22,0.56)$ \\
\hline
\end{tabular}

Values presented as Odds Ratio or Difference ( $95 \%$ confidence interval). Overall health is a score of $0-100$, where higher values indicate better health. A negative effect means that women have lower reported health than men. The other symptom measures compare having any symptoms to no symptoms 
control arise from our findings. These include the need to improve community awareness of hypertension, address poverty and other social determinants of health, reduce out-of-pocket health care expenditures, and consider alternative sites of health care delivery. Community health workers can improve awareness and help to serve as a critical link between communities and the health sector [40]. Efforts to combine economic and financial programs with health care delivery are underway and actively being evaluated $[41,42]$. Kenya, along with many other countries, is expanding universal health coverage in alignment with population health initiatives [43]. Finally, shifting clinical care out of the clinic and into community settings is gaining popularity and support throughout the world [32, 33, 44]. Across all of these strategies, accounting for sex-specific differences, preferences, and patterns will be critical to ensure populationlevel success.

We acknowledge the following limitations in our study. First, the LARK study did not collect any data on individuals who did not consent to participate in the study. We are therefore unable to assess for any differences between participants and non-participants. In addition, we did not evaluate perceptions of quality of care, and it has recently been shown that perception of quality of care can impact care-seeking behavior [45]. The sex of our participants was gathered from clinical data that were linked to the research database instead of being directly reported to the research team. In addition, all data regarding health care utilization, health care costs, and functional status were cross-sectional and self-reported and therefore subject to recall bias. We did not gather information on family income level, and it is quite likely that family members pool financial resources. Similarly, we did not collect data on education level. Lastly, the participants in the study are from rural, agricultural areas, and might not be fully representative of the general population. However, the economic challenges experienced by our study participants are not dissimilar from a large proportion of the global population. In addition, we feel that our analyses contribute to the growing literature on these issues in low-resource settings worldwide.

\section{Conclusions}

Overall, our study found that women face unequal socioeconomic and health status compared to men with elevated blood pressure in rural western Kenya. Our findings reaffirm the need to identify population-specific barriers to seeking healthcare and develop interventions and strategies that might be sex-specific. While our study focuses on the geography of western Kenya, we believe that the findings can be relevant for low-resource, rural settings worldwide.

\section{Abbreviations}

AMPATH: Academic Model Providing Access to Healthcare Partnership: SBP: Systolic blood pressure; DBP: Diastolic blood pressure; KS: Kenyan shilling - local Kenyan currency; NHIF: National Hospital Insurance Fund Kenyan national health insurance; IQR: Interquartile range; LCA: Latent class regression analysis; USD: United States dollars; AIC: Akaike information criterion; OR: Odds ratio; Cl: Confidence interval

\section{Supplementary Information}

The online version contains supplementary material available at https://doi. org/10.1186/s12889-021-10995-3

Additional file 1: Supplemental Table 1. Comparison of different LCA models with different latent classes based on model selection statistics.

Additional file 2: Supplemental Table 2. Description of

demographics in each latent class.

Additional file 3: Supplemental Table 3. Relative risk of latent class membership probability compared to the largest, non-utilizer class.

Additional file 4: Supplemental Figure 1. Estimated distribution of manifest (dependent) variables by latent class for secondary analysis after removing "being told about high blood pressure" manifest variable. Bar graphs showing manifest variable distributions across different utilization and cost parameters in each of the three LCA classes in the secondary analysis.

\section{Acknowledgements}

The authors would like to thank the LARK research team and the staff at AMPATH and the Moi Teaching and Referral Hospital and Moi University.

\section{Authors' contributions}

NS and RV developed the study conception, design, and drafted the manuscript. $\mathrm{AD}$ and $\mathrm{JH}$ assisted with study conception and design, analysed and interpreted data, and assisted with drafting of manuscript. JK, SK, JA, and VO were integral to acquisition of data and analysis and interpretation. VF provided key critical revision. All authors read and approved the final manuscript.

\section{Funding}

No funding sources directly contributed to this study.

Availability of data and materials

The datasets used and/or analyzed during the current study are available from the corresponding author on reasonable request.

\section{Declarations}

\section{Ethics approval and consent to participate}

The LARK study was approved by institutional review boards by all participating institutions engaged in human subjects research, including the Icahn School of Medicine at Mount Sinai, Moi Teaching and Referral Hospital and Moi University. Written informed consent was obtained from all participants.

Consent for publication

Not applicable.

\section{Competing interests}

The authors declare they have no competing interests.

\section{Author details}

${ }^{1}$ Icahn School of Medicine at Mount Sinai, New York, USA. ${ }^{2}$ Center for Statistical Sciences, School of Public Health, Brown University, Providence, RI, USA. ${ }^{3}$ Department of Medicine, Moi University College of Health Sciences, Eldoret, Kenya. ${ }^{4}$ Academic Model Providing Access to Healthcare (AMPATH), Eldoret, Kenya. ${ }^{5}$ Department of Biostatistics, Brown University School of Public Health, Providence, RI, USA. ${ }^{6}$ Department of Population Health, NYU Grossman School of Medicine, New York, NY, USA. 


\section{Received: 9 October 2020 Accepted: 6 May 2021} Published online: 19 May 2021

\section{References}

1. Stanaway JD, Afshin A, Gakidou E, Lim SS, Abate D, Abate KH, et al. Global, regional, and national comparative risk assessment of 84 behavioural, environmental and occupational, and metabolic risks or clusters of risks for 195 countries and territories, 1990-2017: a systematic analysis for the global burden of disease study 2017. Lancet. 2018;392(10159):1923-94.

2. Kelly BB, Fuster V. Promoting cardiovascular health in the developing world: a critical challenge to achieve global health. Washington, DC: National Academies Press; 2010.

3. Bovet P, Gervasoni J-P, Mkamba M, Balampama M, Lengeler C, Paccaud F. Low utilization of health care services following screening for hypertension in Dar Es Salaam (Tanzania): a prospective population-based study. BMC Public Health. 2008;8(1):1-8.

4. Abaerei AA, Ncayiyana J, Levin J. Health-care utilization and associated factors in Gauteng province, South Africa. Global Health Action. 2017;10(1): 1305765. https://doi.org/10.1080/16549716.2017.1305765.

5. Cleary PD, Mechanic D, Greenley JR. Sex differences in medical care utilization: an empirical investigation. J Health Soc Behav. 1982;23(2):106-19. https://doi.org/10.2307/2136508.

6. Bertakis KD, Azari R, Helms LJ, Callahan EJ, Robbins JA. Gender differences in the utilization of health care services. J Fam Pract. 2000;49(2):147-52.

7. Mustard CA, Kaufert P, Kozyrskyj A, Mayer T. Sex differences in the use of health care services. N Engl J Med. 1998;338(23):1678-83. https://doi.org/1 0.1056/NEJM199806043382307.

8. Andersen R, Newman JF. Societal and Individual Determinants of Medical Care Utilization in the United States. Milbank Q. 2005;83(4):95-124 Onlineonly-Online-only.

9. Fernández-Olano C, Hidalgo JDL-T, Cerdá-Díaz R, Requena-Gallego M, Sánchez-Castaño C, Urbistondo-Cascales $L$, et al. Factors associated with health care utilization by the elderly in a public health care system. Health Policy. 2006;75(2):131-9. https://doi.org/10.1016/j.healthpol.2005.02.005.

10. Foti K, Wang D, Appel LJ, Selvin E. Hypertension awareness, treatment, and control in US adults: trends in the hypertension control cascade by population subgroup (National Health and Nutrition Examination Survey, 1999-2016). Am J Epidemiol 2019;188:2165-2174 [cited 2020 Jan 19]; Available from: https://doi.org/10.1093/aje/kwz177/5561425

11. Labor force, female (\% of total labor force) | Data [cited 2019 Jun 1]. Available from: https://data.worldbank.org/indicator/SL.TLF.TOTL.FE.ZS. Accessed 1 June 2018

12. The Gender Wage Gap. Earnings differences by gender, race, and ethnicity: Institute for Women's Policy Research; 2017. [cited 2019 Jun 1]. Available from: https://iwpr.org/publications/gender-wage-gap-2017/

13. Vedanthan R, Kamano JH, DeLong AK, Naanyu V, Binanay CA, Bloomfield GS, et al. Community health workers improve linkage to hypertension Care in Western Kenya. J Am Coll Cardiol. 2019;74(15):1897-906. https://doi.org/10.1 016/j.jacc.2019.08.003.

14. Frawley A, Rotich J, Delong AK, Menya D, Naanyu V, Horowitz CR, et al. PS015 hypertension related skills retention among community health Workers in Rural Western Kenya: process evaluation of the Lark hypertension study. Glob Heart. 2016;2(11):e18

15. Einterz RM, Kimaiyo S, Mengech HN, Khwa-Otsyula BO, Esamai F, Quigley F, et al. Responding to the HIV pandemic: the power of an academic medical partnership. Acad Med. 2007:82(8):812-8. https://doi.org/10.1097/ACM.0b013 e3180cc29f1.

16. EQ-5D. [cited 2020 Apr 13]. Available from: https://euroqol.org/. Accessed 13 Apr 2020.

17. R: The R Project for Statistical Computing [cited 2019 Jun 29]. Available from: https://www.r-project.org/. Accessed 29 June 2019.

18. Schreiber JB. Latent class analysis: an example for reporting results. Res Soc Adm Pharm. 2017;13(6):1196-201. https://doi.org/10.1016/j.sapharm.2016.11. 011.

19. Linzer DA, Lewis JB. poLCA: an R package for Polytomous variable latent class analysis. J Stat Softw. 2011:42(1):1-29.

20. Organization WH. An empirical model of access to health care, health care expenditure and impoverishment in Kenya: learning from past reforms and lessons for the future. Geneva: World Health Organization; 2006.
21. Everett B, Zajacova A. Gender differences in hypertension and hypertension awareness among young adults. Biodemography Soc Biol. 2015;61(1):1-17. https://doi.org/10.1080/19485565.2014.929488.

22. Ochieng-Ooko V, Ochieng D, Sidle JE, Holdsworth M, Wools-Kaloustian K, Siika AM, et al. Influence of gender on loss to follow-up in a large HIV treatment programme in western Kenya. Bull World Health Organ. 2010 Sep;88(9):681-8. https://doi.org/10.2471/BLT.09.064329.

23. Freidoony L, Chhabi R, Kim CS, Park MB, Kim C-B. The components of selfperceived health in the Kailali District of Nepal: a cross-sectional survey. Int $J$ Environ Res Public Health. 2015;12(3):3215-31. https://doi.org/10.3390/ ijerph120303215.

24. Fylkesnes K. Determinants of health care utilization — visits and referrals. Scand J Soc Med. 1993;21(1):40-50. https://doi.org/10.1177/1403494893021 00107.

25. Balkrishnan R, Anderson RT, Bowton D. Self-reported health status predictors of healthcare services utilization and charges in elderly asthmatic patients. J Asthma. 2000;37(5):415-23. https://doi.org/10.3109/02770900009055467.

26. Wozniak G, Khan T, Gillespie C, Sifuentes L, Hasan O, Ritchey M, et al. Hypertension control Cascade: a framework to improve hypertension awareness, treatment, and control. J Clin Hypertens. 2016;18(3):232-9. https://doi.org/10.1111/jch.12654.

27. Geldsetzer P, Manne-Goehler J, Marcus M-E, Ebert C, Zhumadilov Z, Wesseh $\mathrm{CS}$, et al. The state of hypertension care in 44 low-income and middleincome countries: a cross-sectional study of nationally representative individual-level data from 1.1 million adults. Lancet. 2019;394(10199):652-62. https://doi.org/10.1016/S0140-6736(19)30955-9.

28. Atchessi N, Ridde V, Abimbola S, Zunzunegui M-V. Factors associated with the healthcare-seeking behaviour of older people in Nigeria. Arch Gerontol Geriatr. 2018;79:1-7. https://doi.org/10.1016/j.archger.2018.07.015.

29. Moy E, Bartman BA, Weir MR. Access to hypertensive care: effects of income, insurance, and source of care. Arch Intern Med. 1995;155(14):1497502. https://doi.org/10.1001/archinte.1995.00430140063005

30. Kenya National Bureau of Stastics. Kenya Integrated Household Budget Survey; 2018.

31. Maichou L, Xiong P, Park L, Schwei RJ, Jacobs EA. Western or traditional healers? Understanding decision making in the Hmong population. West J Nurs Res. 2017;39(3):400-15.

32. Victor RG, Lynch K, Li N, Blyler C, Muhammad E, Handler J, et al. A clusterrandomized trial of blood-pressure reduction in black barbershops. $\mathrm{N}$ Engl J Med. 2018;378(14):1291-301. https://doi.org/10.1056/NEJMoa1717250.

33. Schoenthaler A, Lancaster K, Midberry S, Nulty M, Ige E, Palfrey A, et al. The FAITH trial: baseline characteristics of a church-based trial to improve blood pressure control in blacks. Ethn Dis. 2015;25(3):337-44. https://doi.org/10.1 8865/ed.25.3.337.

34. FAQs: Global Poverty Line Update. World Bank. [cited 2021 Feb 14]. Available from: https://www.worldbank.org/en/topic/poverty/brief/globalpoverty-line-faq. Accessed 14 Feb 2021.

35. Kenya - The World Factbook. [cited 2021 Feb 14]. Available from: https:// www.cia.gov/the-world-factbook/countries/kenya/\#economy

36. Kenya | World Bank Data. The World Bank. [cited 2021 Feb 21]. Available from: https://data.worldbank.org/country/KE. Accessed 21 Feb 2021.

37. Bukhman G, Mocumbi AO, Atun R, Becker AE, Bhutta Z, Binagwaho A, et al. The lancet NCDI poverty commission: bridging a gap in universal health coverage for the poorest billion. Lancet. 2020;396(10256):991-1044. https:// doi.org/10.1016/S0140-6736(20)31907-3.

38. Mberu BU, Haregu TN, Kyobutungi C, Ezeh AC. Health and health-related indicators in slum, rural, and urban communities: a comparative analysis. Glob Health Action. 2016;9(1):33163. https://doi.org/10.3402/gha.v9.33163.

39. Johnson ME, Brems C, Warner TD, Roberts LW. Rural-urban health care provider disparities in Alaska and New Mexico. Adm Policy Ment Health Ment Health Serv Res. 2006;33(4):504-7. https://doi.org/10.1007/s10488-0050001-7.

40. He J, Irazola V, Mills KT, Poggio R, Beratarrechea A, Dolan J, et al. Effect of a community health worker-led multicomponent intervention on blood pressure control in low-income patients in argentina: a randomized clinical trial. JAMA. 2017;318(11):1016-25.

41. Pastakia SD, Manyara SM, Vedanthan R, Kamano JH, Menya D, Andama B, et al. Impact of bridging income generation with group integrated care (BIGPIC) on hypertension and diabetes in rural Western Kenya. J Gen Intern Med. 2017:32(5):540-8. https://doi.org/10.1007/s11606-016-3918-5. 
42. Vedanthan $\mathrm{R}$, Kamano JH, Lee H, Andama B, Bloomfield GS, DeLong AK, et al. Bridging income generation with group integrated care for cardiovascular risk reduction: rationale and design of the BIGPIC study. Am Heart J. 2017;188:175-85. https://doi.org/10.1016/j.ahj.2017.03.012.

43. Mercer T, Gardner A, Andama B, Chesoli C, Christoffersen-Deb A, Dick J, et al. Leveraging the power of partnerships: spreading the vision for a population health care delivery model in western Kenya. Global Health. 2018:14(1):44.

44. Boivin JM, Risse J, Laurière E, Burnier M. Screening for hypertension at the hairdresser: a feasibility study in France and Morocco. Blood Press. 2020;13: $1-7$.

45. Bell G, Macarayan EK, Ratcliffe H, Kim J-H, Otupiri E, Lipsitz S, et al. Assessment of bypass of the nearest primary health care facility among women in Ghana. JAMA Netw Open. 2020;3(8):e2012552. https://doi.org/1 0.1001/jamanetworkopen.2020.12552.

\section{Publisher's Note}

Springer Nature remains neutral with regard to jurisdictional claims in published maps and institutional affiliations.

Ready to submit your research? Choose BMC and benefit from:

- fast, convenient online submission

- thorough peer review by experienced researchers in your field

- rapid publication on acceptance

- support for research data, including large and complex data types

- gold Open Access which fosters wider collaboration and increased citations

- maximum visibility for your research: over $100 \mathrm{M}$ website views per year

At BMC, research is always in progress.

Learn more biomedcentral.com/submissions 